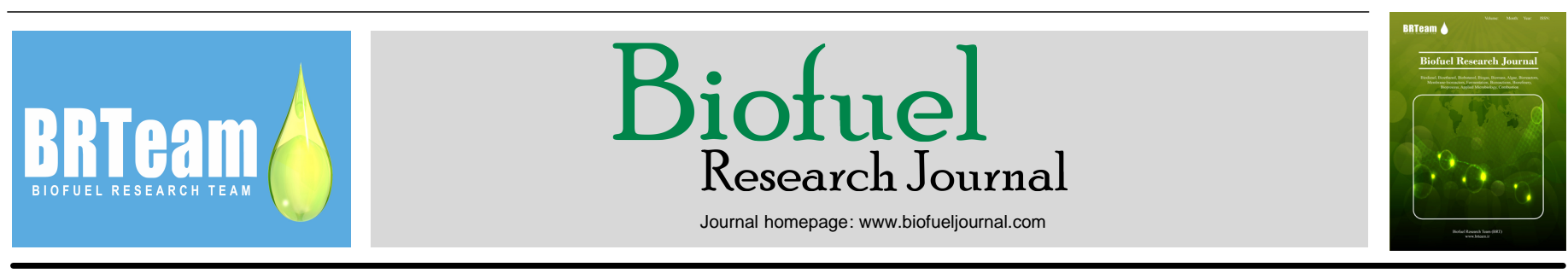

\title{
Editorial
}

\section{Biodiesel: hopes and dreads}

The use of vegetable oils in diesel engine could be dated back to 1893 when German inventor Rudolf Diesel employed peanut oil. However, the lower cost and higher availability of petrol-diesel completely boycotted vegetable oils in 1920. Accordingly, diesel engines were retrofitted to work with fossil-based diesel having a lower viscosity. The use of natural oils as alternative energy was proposed again in the early 1980 because of fossil fuels supply shortages, environmental concerns and energy security. The commercial application of natural oils as diesel fuel was re-started in the late 1990. However, direct use of vegetable oils in modified diesel engines results in poor atomization as well as coking the injectors and combustion chamber, due to their higher viscosity and lower volatility. To solve these issues, several unsuccessful strategies including dilution and micro-emulsification were explored. Moreover, some efficient remedies such as pyrolysis, supercritical methanol, and transesterification were also examined to reduce the higher viscosity of natural oils. The last approach has been shown to be most promising to overcome the high viscosity problem by converting the natural oils into their alkyl esters called "biodiesel". Biodiesel can be used in existing diesel engines with little or no modifications owing to its similar physical properties to those of mineral diesel. Besides renewability, environmental sustainability concerns due to excessive use of fossil fuels, have also highlighted the surge of interest in biodiesel. Unlike petro-diesel, biodiesel is biodegradable and nontoxic and can substantially decrease the amount of exhaust emissions, particularly unburned hydrocarbon, particulates materials, and carbon monoxide.

However, in reality biodiesel can be characterized as a double-edged sword with both positive and negative impacts. Biodiesel proponents claim that it has the potential to be "carbon-neutral" over its life cycle and can lead to a cleaner combustion. However, biodiesel opponents argue that being overzealous about its large-scale production can negatively affect food prices and food security. Moreover, some environmental groups express that biodiesel could results in massive deforestation. Generally, biodiesel can be produced from a variety of feedstocks including (1) original vegetable oils such as palm, soybean, and rapeseed oils; (2) animal fats such as tallow, lard, and yellow grease; and (3) non-edible oils such as jatropha, karanja, neem oil, castor oil, algae, etc.; and (4) waste vegetable oil. At the current state, the first category can only replace petrol-diesel global consumption by a small percentage of up to about 3\% if all of the produced food-grade oils are transesterified. Moreover, the second group can also only substitute a very small fraction of mineral diesel if their other applications are discarded. On the other hand, it is unfortunate that the excitement of the biodiesel industry in non-edible oils production as sustainable biodiesel feedstocks faded away since these feedstocks were found not financially viable. For instance, China has stagnated the Jatropha curcas development and production and Mexico has also abandoned its plantation. Furthermore, it should be noted that widespread planting of non-edible oils could result in over-fertilization, pesticide use, and land-use conversion. Whilst, production of non-edible vegetable oils in marginal lands can only cover a trivial fraction of the overall diesel fuel required.

In the past decade, hopes for finding a substitute for vegetable oil have directed the biodiesel industry towards algae to surmount the food $v$ s. fuel debate. In line with that, strong advocacy surfaced the literature indicating that algae could outperform the best-performing vegetable oil resources (by more than 200 times) and could produce oil as much as about $50 \%$ of its weight when cultivated in brackish or salt water while capturing harmful $\mathrm{CO}_{2}$ too. Unfortunately, algae biodiesel busted as fast as it boomed. For instance, the national renewable energy laboratory (NREL) terminated two decades of algal biodiesel research because of its extensive need for costly nutrients like nitrogen and phosphorous. Furthermore, Exxon Mobil Corp. algae biofuels program fell flat after investing over $\$ 100$ million since it failed to achieve economically viable results. Hence, only biodiesel produced from waste cooking oil could be regarded as a sustainable, economical feedstock for biodiesel production, the available resources are limited though.

It is worth mentioning that although one of the most important driving forces behind the development of biodiesel is to hope for a reduction in dependence on fossil fuels, almost all of the stages involved in the production of its feedstock and synthesis are tied up with application of fossil fuels. In addition to that, lower energy content of biodiesel, large amount of glycerol produced, high water consumption during the downstream processes, and poor cold properties could be mentioned as the main drawbacks of biodiesel widespread utilization. Therefore, these challenges should be overcome by future efforts in order to strengthen the environmentally-benign aspects of biodiesel.

In conclusion and given the discussion presented above, only the application of waste-oriented oils such as waste cooking oil for biodiesel production and biodiesel inclusion ratios of below 5\% (owing to resource limitation) could be suggested as an environmentally-acceptable and sustainable strategy for the next few decades (short-term timescale). It should be noted that the application of liquid biofuels in general in the transportation sector is anticipated to fade away gradually after this time frame. This is ascribed to the fact that the other promising renewable energy technologies in particular photovoltaic and fuel cell systems are being developed very swiftly and should be gradually taking over liquid biofuels such as biodiesel in the transportation system. In better words, thanks to the enormous developments in the renewable electricity production and storage systems, it is envisaged that viable and inexpensive electric and hybrid vehicles will be available at mid- and long-term timescales for more sustainable and environmentallyfriendly transportation and power generation.

Editors

Mortaza Aghbashlo University of Tehran, Iran Email Address: maghbashlo@ut.ac.ir

Ayhan Demirbas King Abdulaziz University, Saudi Arabia Email Address: ademirbas@kau.edu.sa

(C) 2016 BRTeam. All rights reserved. 